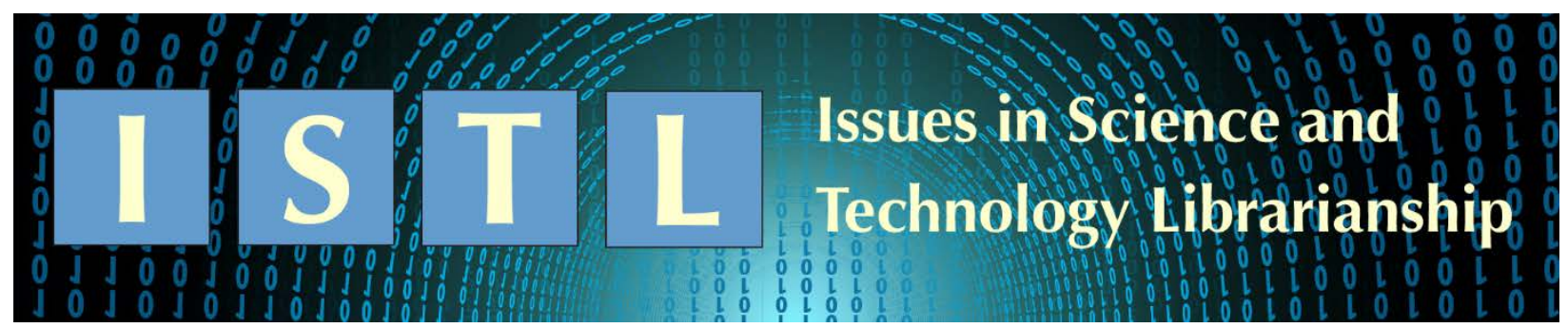

Tips from the Experts: The Engineer Library

\author{
Emily Dommermuth \\ Science \& Engineering Librarian \\ Emily.Dommermuth@Colorado.edu \\ Mark Locy \\ Outreach and Student Success Specialist \\ Mark.Locy@Colorado.edu
}

\begin{abstract}
Leonard H. Gemmill Engineering, Mathematics \& Physics Library
University of Colorado Boulder

Boulder, Colorado
\end{abstract}

\title{
Introduction
}

A recent trend in libraries has been to offer Living Library or Human Library ${ }^{\mathrm{TM}}$ events (Granger 2017). The idea of using people as a source of information in a library led to the idea of hosting an event in the Gemmill Engineering, Math \& Physics Library at the University of Colorado Boulder, where engineering students could meet and learn from professional engineers. Engineering curricula are highly structured and intense, and new students struggle to decide or change their engineering focus. These issues lead to problems with retention, as students may drop out of college or choose a non-engineering major when they discover how difficult it will be to change their major. Students face increased financial burdens when changing majors later in their college career, as they must often add classes to their course plans and delay graduation.

Providing students with a chance to talk to practicing engineers to learn what those engineers do might provide some clarity in career direction, which can help students persist to graduation (Sandler 2000; Kreysa 2006; Willcoxson \& Wynder 2010). Another interesting aspect of hosting a library event in which students can use people as a source of information is the connection to workplace information literacy. Research on the use of information in the engineering workplace highlights the importance of people as information sources (Hertzum \& Pejtersen 2000; Tenopir \& King 2004; Allard et al. 2009). Finally, underrepresented students, including minority, female, and first-generation students, might have fewer chances to interact with professional engineers in their pre-collegiate lives. Hosting an event for students to talk with professional engineers benefits all engineering students and can be especially impactful for underrepresented students.

The Engineer Library Event was funded by an Innovative Inclusion Idea grant from CU Boulder's College of Engineering and Applied Sciences' BOLD Center and Department of Computer Science. The BOLD Center engages underrepresented students in engineering. The event was held in February of 2018. 


\section{The Engineer Library}

Eight professional engineers were welcomed to the Gemmill Engineering, Math \& Physics Library at CU Boulder with parking vouchers and catered sandwiches for lunch. The engineers represented most disciplines within engineering, as well as female engineers and ethnic/racial minorities. The engineers were seated in chairs that were grouped casually around the library (Figure 1).

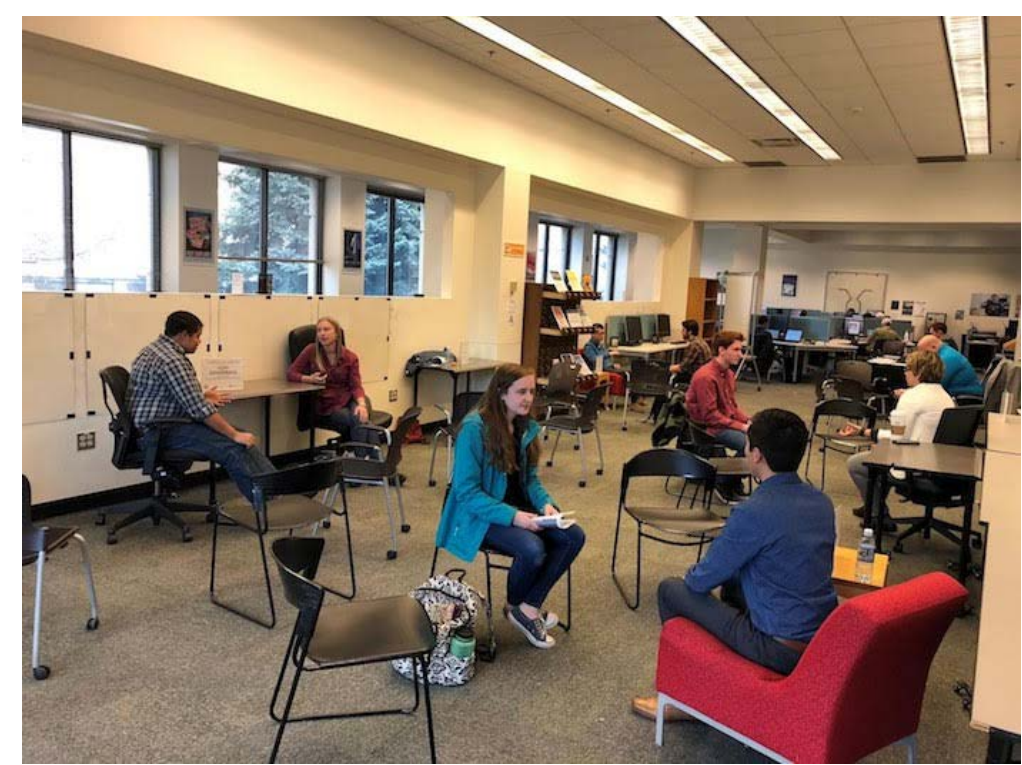

Figure 1. Students talk with practicing engineers during the Engineer Library Event at the Gemmill Engineering, Math \& Physics Library.

Each engineer had a biographical sign posted near them so students could identify the engineer and the kind of work they did. In the library's lobby, a team of librarians staffed a welcome table to tell students about the event, sign them in, provide them with programs and a snack incentive. From the sign-in table students casually moved around the area where the engineers were sitting, and engaged in conversation and informational interviews with the engineers. Informational interviewing is not a networking or job-searching activity, it is an information gathering tool for interviewers to learn about the field. Approximately 70 students attended the event.

\section{Assessment}

We gathered both informal and formal feedback about the event. Talking with engineers and students during the event provided informal feedback, and both groups indicated that they enjoyed the event and thought it was beneficial. Formal assessment of the event entailed a postevent survey sent to all volunteer engineers and a separate post-event survey sent to 57 students who signed in with their e-mail addresses during the event. Six engineers responded to their survey, and 16 students responded to their survey.

\section{Professional Engineer Feedback}

All of the professional engineers who completed the survey indicated that they would volunteer at an event like this again in the future, and that they would recommend the event to colleagues. 
We asked the engineers to estimate the number of students they spoke to at the event, and the answers ranged from five students to 20 students, with the average being about 10 students. We received a number of helpful suggestions for future events, including to have engineers tally the number of students they spoke to. The engineers commented that they "Enjoyed having the chance to speak to future leaders and engineers," they liked "the informal setting and casual atmosphere of the event," and they wish they could have attended similar events when they themselves were students.

\section{Student Attendee Feedback}

Ninety-four percent of the students who took the survey indicated that the event was helpful, and all of the respondents said they would recommend the event. The survey respondents were asked to estimate the number of engineers they spoke to, and the number ranged from zero to all eight engineers, with the average being three. The students represented a variety of majors (Figure 2) and were at various stages of their academic careers (Figure 3).

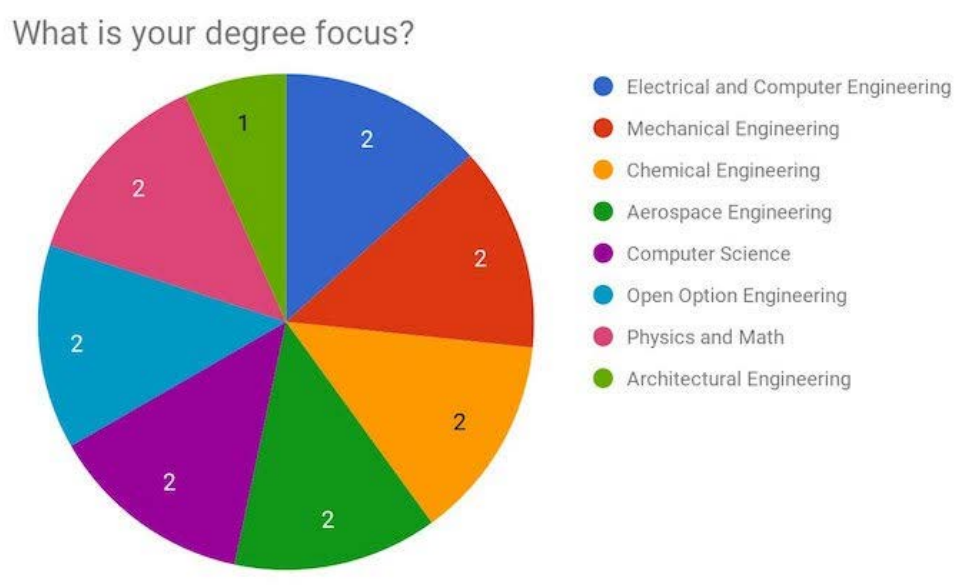

Figure 2: Count of the majors of student survey respondents who attended the Engineer Library Event.

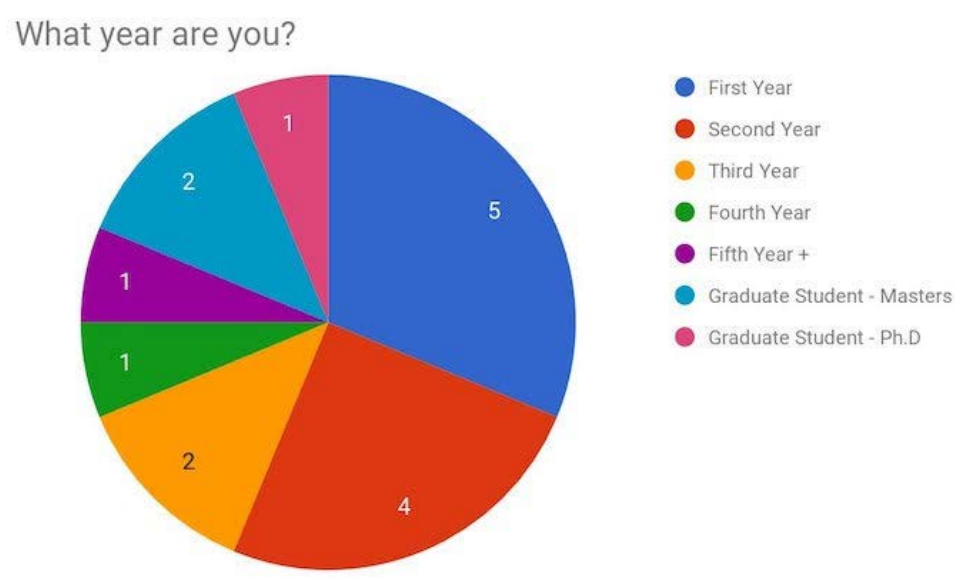

Figure 3: Count of the degree years of student survey respondents who attended the Engineer Library Event. 
Students provided feedback to help us improve the event next year, including information about the most effective marketing strategies. They shared insights about what they learned from the event and how the event helped inform their career goals. Several students had comments similar to this one: "don't worry too much about making sure your major is what you want to do for the rest of your life. So long as you're interested in engineering generally, you'll be able to find your niche once you're in industry." In contrast several students indicated that the event helped affirm their choice of major within engineering, and what day-to-day work in a job in that field might be like. Students appreciated "talking to someone real, in a less formal way" and that they got "ideas of our next step." They received advice about joining student organizations, classes to consider taking, internships, and networking from the professional engineers.

\section{Best Practices}

The Engineer Library was successful and has been funded again for 2019. We learned that the most effective marketing tactic was asking academic advisors and faculty to encourage their students to attend the event. Providing a small snack as an incentive to students to attend the event was another important marketing tool. We aim to have more professional engineers attend the event, and to have even better inclusion of all the engineering disciplines. Including women, LGBTQ, and racial and ethnic minority engineers is important in order to engage students from underrepresented backgrounds, so they can see themselves reflected in the profession. Providing parking, food, and a thank you gift to make the engineers visit to campus enjoyable was important, as engineers volunteered their time away from work. The engineers were appreciative of the lunch and thank you gift we provided.

\section{Conclusions}

The Engineer Library event was an innovative program that engaged students with the library and professional engineers in an authentic way. When students typically view the library only as a place to study and find books, events like the Engineer Library can help expand their thinking about the role of the library. Engineers use information sources beyond traditional academic sources, and students are often using classmates and online videos more than books and scholarly articles. They are still engaging with information, and the library should be engaging with their authentic information practices to encourage them to think critically about information. Bringing people into the library to serve as an information source lets students know that the library is a place they can engage with information of all kinds. The library can be a valuable resource for them to succeed as engineering students, and in their future careers as practicing engineers.

\section{References}

Allard, S., Levine, K.J., and Tenopir, C. 2009. Design engineers and technical professionals at work: Observing information usage in the workplace. Journal of the American Society for Information Science and Technology 60(3):443-454. DOI: 10.1002/asi.21004

Hertzum, M. and Pejtersen, A.M. 2000. The information-seeking practices of engineers: Searching for documents as well as for people. Information Processing \& Management 36(5):761-778. DOI: 10.1016/S0306-4573(00)00011-X 
Kreysa, P.G. 2006. The impact of remediation on persistence of under-prepared college students. Journal of College Student Retention: Research, Theory \& Practice 8(2):251-270. DOI: 10.2190/C90C-PHWY-G6B2-1N5E

Granger, L. 2017. If these books could talk. American Libraries 48(6):20-23.

Sandler, M.E. 2000. Career decision-making self-efficacy, perceived stress, and an integrated model of student persistence: a structural model of finances, attitudes, behavior, and career development. Research in Higher Education 41(5):537-580. DOI: 10.1023/A:1007032525530

Tenopir, C. and King, D.W. 2004. Communication patterns of engineers. Hoboken (NJ): IEEE Press.

Willcoxson, L. and Wynder, M. 2010. The relationship between choice of major and career, experience of university and attrition. Australian Journal of Education 54(2):175-189. DOI: $\underline{10.1177 / 000494411005400205}$

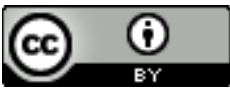

This work is licensed under a Creative Commons Attribution 4.0 International License. 